\title{
Measuring Connection to Nature-A Illustrated Extension of the Inclusion of Nature in Self Scale
}

\author{
Matthias Winfried Kleespies ${ }^{1, *}$, Tina Braun ${ }^{1}$, Paul Wilhelm Dierkes ${ }^{1}$ (D) and Volker Wenzel ${ }^{2}$ \\ 1 Bioscience Education and Zoo Biology, Goethe-University Frankfurt, 60438 Frankfurt, Germany; \\ braun@bio.uni-frankfurt.de (T.B.); dierkes@bio.uni-frankfurt.de (P.W.D.) \\ 2 Bioscience Education, Goethe-University Frankfurt, 60438 Frankfurt, Germany; wenzel@bio.uni-frankfurt.de \\ * Correspondence: kleespies@em.uni-frankfurt.de; Tel.: +49-69-798-42276
}

Citation: Kleespies, M.W.; Braun, T.; Dierkes, P.W.; Wenzel, V. Measuring Connection to Nature-A Illustrated Extension of the Inclusion of Nature in Self Scale. Sustainability 2021, 13, 1761. https://doi.org/10.3390/ su13041761

Academic Editor: Christoph Randler

Received: 15 January 2021

Accepted: 3 February 2021

Published: 6 February 2021

Publisher's Note: MDPI stays neutral with regard to jurisdictional claims in published maps and institutional affiliations.

Copyright: (c) 2021 by the authors. Licensee MDPI, Basel, Switzerland. This article is an open access article distributed under the terms and conditions of the Creative Commons Attribution (CC BY) license (https:// creativecommons.org/licenses/by/ $4.0 /)$.

\begin{abstract}
The human-nature connection is an important factor that is frequently the subject of environmental education research and environmental psychology. Therefore, over the years, numerous measuring instruments have been established to quantitatively record a person's connection to nature. However, there is no instrument specifically for children with cognitive limitations. For this reason, in this study, an established scale for connection to nature, the inclusion of nature in self scale (INS), was modified especially for the needs of this group. Study 1 investigated what students understand by the term "nature" in order to create an illustrated version of the INS. In study 2, the new instrument was tested on university students and compared with the original INS and the connectedness to nature scale (CNS). No significant differences between the original INS and the new developed scale were found $(p=0.247)$, from which it can be concluded that the illustrated INS (IINS) measures the connection to nature with similar accuracy as the original INS. In study 3, the instrument was tested together with other established nature connection instruments on the actual target group, students with disabilities. The correlation between the IINS, the CNS, and nature connectedness scale (NR) were in accordance with the expected literature values $\left(r_{\text {IINS-CNS }}=0.570 \& r_{\text {IINS-NR }}=0.605\right)$. The results of this study also prove effectiveness of the developed illustrated scale. This research thus provides a suitable measuring instrument for people with learning difficulties and can make a contribution to the investigation of human-nature connections and conservation education.
\end{abstract}

Keywords: connection to nature; inclusion of nature in self scale (INS); illustrated inclusion of nature in self scale (IINS); connectedness to nature scale (CNS); nature relatedness scale (NR); special needs education; learning difficulties

\section{Introduction}

"We abuse land because we regard it as a commodity belonging to us. When we see land as a community to which we belong, we may begin to use it with love and respect." [1]. With this well-known quotation, the ecologist Leopold described the human connection to nature. Nature and the land should not be seen as property, but as part of that which we belong to. In current environmental education research, the concept of connection to nature plays an important role in this context. Although the construct of connection to nature is repeatedly applied in various fields such as environmental research, conservation education, and environmental psychology, there is still no clear and generally accepted definition. Some authors, for example, focus in their concept of connection to nature particularly on the relationship between one's own identity and nature [2,3]. Other authors emphasize the emotional connection to nature [4-6].

In our modern Western society, however, the connection of people to nature is decreasing more and more. This split between humans and nature can be seen as one of the reasons for our current environmental problems [7]. Connection to nature is a predictor for environmentally friendly behavior $[5,6]$ and can increase the positive environmental action of a person [8]. There is a positive correlation between connection to nature and 
appropriate environmental behavior [9] and people with an increased connection to nature have a higher motivation to show environmentally friendly behavior $[2,10,11]$. Therefore, the connection to nature is an important basis for the protection of nature (e.g., [4,12-14]). However, an increase in connection with nature not only offers advantages for the environment, but also great individual benefit. People that are connected to nature generally have a higher sense of well-being [15-17], show better mental health [15], are happier [18,19], and have a higher life vitality [20].

A number of studies have shown that environmental education programs are one way of increasing the participants' connection to nature [21-24]. In this context, a large number of measuring instruments have been developed in recent years to investigate the connection to nature of humans: For example the Connectedness to Nature Scale (CNS) by Mayer and Frantz [5], the Nature Relatedness Scale (NR) by Nisbet et al. [6], the Environmental Identity Scale by Clayton [2], the Implicit Association Test (IAT) by Schultz et al. [25] or the Children's Connection to Nature Index by Cheng and Monroe [11].

In his concept of "Inclusion of Nature in Self" Schultz [12] describes three levels of inclusion with nature. The cognitive component indicates how strongly a person sees nature as part of himself or herself, the affective component answers the question whether a person cares about nature and the behavioral component explains whether a person is motivated to act in the best interests of nature. The cognitive component is the prerequisite for achieving the affective component and the affective component in turn is the prerequisite for the behavioral component (Figure 1).

\section{Inclusion}

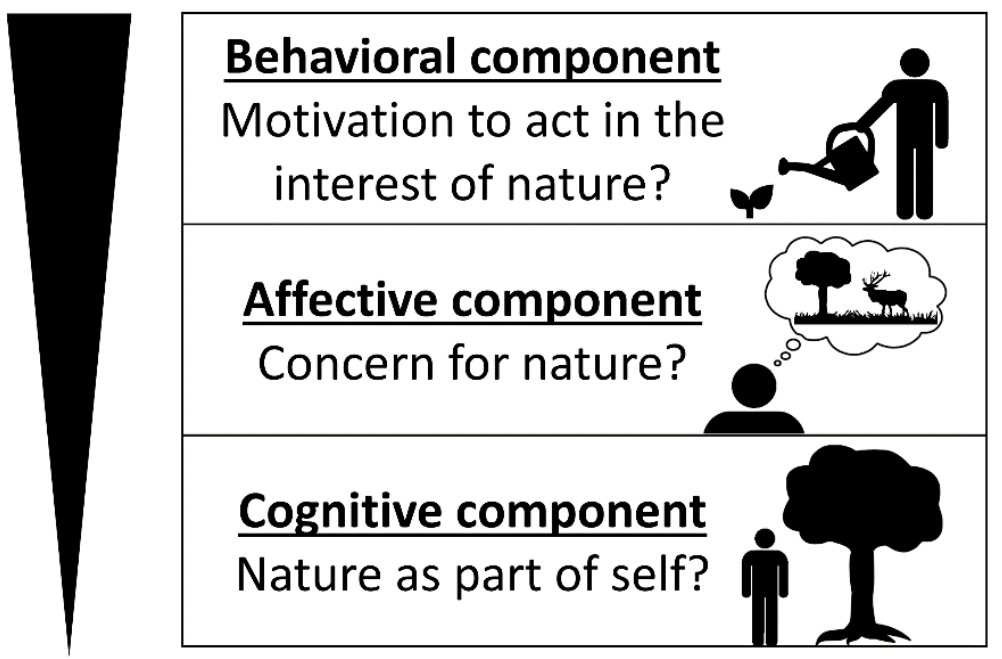

\section{Exclusion}

Figure 1. The concept of Inclusion of Nature by Schultz (2002).

To measure the Inclusion of Nature, Schultz [12] introduced the "Inclusion of nature in self scale" (INS). This measuring instrument consists only of a single graphical question (Appendix A), which has several advantages: It can be used quickly and easily, requires little space in a questionnaire, no complex translations are necessary and the results from different cultures remain comparable. Furthermore, this measuring instrument also shows a high validity [26]. However, despite the many advantages, there are also points of criticism. Due to the single item structure, the reliability of the construct cannot be verified [25] and the participants must have a certain capability of abstraction to understand the scale correctly [5]. While the reliability of the scale has already been confirmed by an extended version of the scale in another study [26], there is, however, not yet a version of the scale for participants with a lower level of imagination and abstraction. Especially when examining the connection to nature of younger students or of people in need of support, this would 
make sense, since exactly these groups of people potentially do not have the necessary ability to abstract. Therefore, in this study an extended illustrated version of the INS will be developed, tested and compared with established connection to nature scales. In a first step (study 1), it will be investigated what school children understand by the term "nature". This step is necessary to determine what children understand by the complex and multi-layered concept of nature in the first place. With the help of these findings, a new illustrated version of the INS was developed. This new measuring instrument was then tested on two groups of students and compared with the CNS and the original INS to verify its validity (study 2). If the new instrument shows high validity, there should be no difference between the tested groups. Subsequently, the illustrated version of the INS was tested on the actual target group (children with learning difficulties) and compared with the CNS and NR. If the newly developed instrument has high validity, it can be expected that the correlations in this comparison will be consistent with the values found in the literature (study 3 ).

\section{Study 1}

In recent years, various definitional approaches have been proposed that are more or less able to describe the complexity of nature $[4,27,28]$, but especially in the research of human-nature connections in environmental-psychology the term nature often remains undefined [29]. An illustrated representation of "nature" is therefore not an easy task, since the definitions of "nature" differ culturally and historically [30]. Most current definitions describe nature as all things that exist independently from humans, such as animals, plants, but also the inanimate parts of nature (e.g., mountains, weather, waters, etc.) $[31,32]$. The aim of the first study was to determine what children understand by the term nature in order to develop a suitable illustrated questioning instrument.

\subsection{Methods}

The mentioned lack of empirical research concerning nature images of children and young adults made a theory-guided, hypothesis-testing investigation nearly impossible. Thus, this research followed a descriptive-exploratory design (Bortz and Döring, 2006). This sub-study, which was conducted in Germany in 2014 and 2015, presents data from a quantitative survey comparing ideas of nature reported by individuals.

\subsubsection{Participants}

The comparative study exploring individual ideas of nature is based on a survey which included $\mathrm{N}=183$ students ( $45.9 \%$ female, $54.1 \%$ male). Two primary and seven secondary school classes from Germany were surveyed ( $8 \%$ were between 7 and 9 years of age, $67.76 \%$ between 10 and 12 years and $23.5 \%$ between 13 and 15 years). Recruitment of participants happened via mail advertisement. There were 20 schools in Germany invited to participate in the environmental research study. All program participants were aware that their assessment was purely voluntary. As most of the participants were minors, parental consent was gained prior to the evaluation. All students and parents were informed about the detailed study contents, the research process, and data storage.

\subsubsection{Instruments}

Data was assessed via paper and pencil questionnaire. In addition to demographic data, the instrument focused on the images of nature using an open-ended item. The participants had to name up to three items that are essential parts of nature for them.

\subsubsection{Analysis}

The evaluation quantified how often individual components of nature were mentioned. For terms that occurred more frequently ( $>5$; e.g., trees), a separate category was added and these were then not placed in a top category (e.g., plants or forest). On the other hand, terms with only a few mentions $(<5)$ were assigned to a suitable top category (e.g., insects 
to animals). Green was used as a collective category for naming the color green, leaves or grass.

\subsection{Results}

A total of 16 categories with more than five entries were recorded, whose percentage distribution is shown in Figure 2.

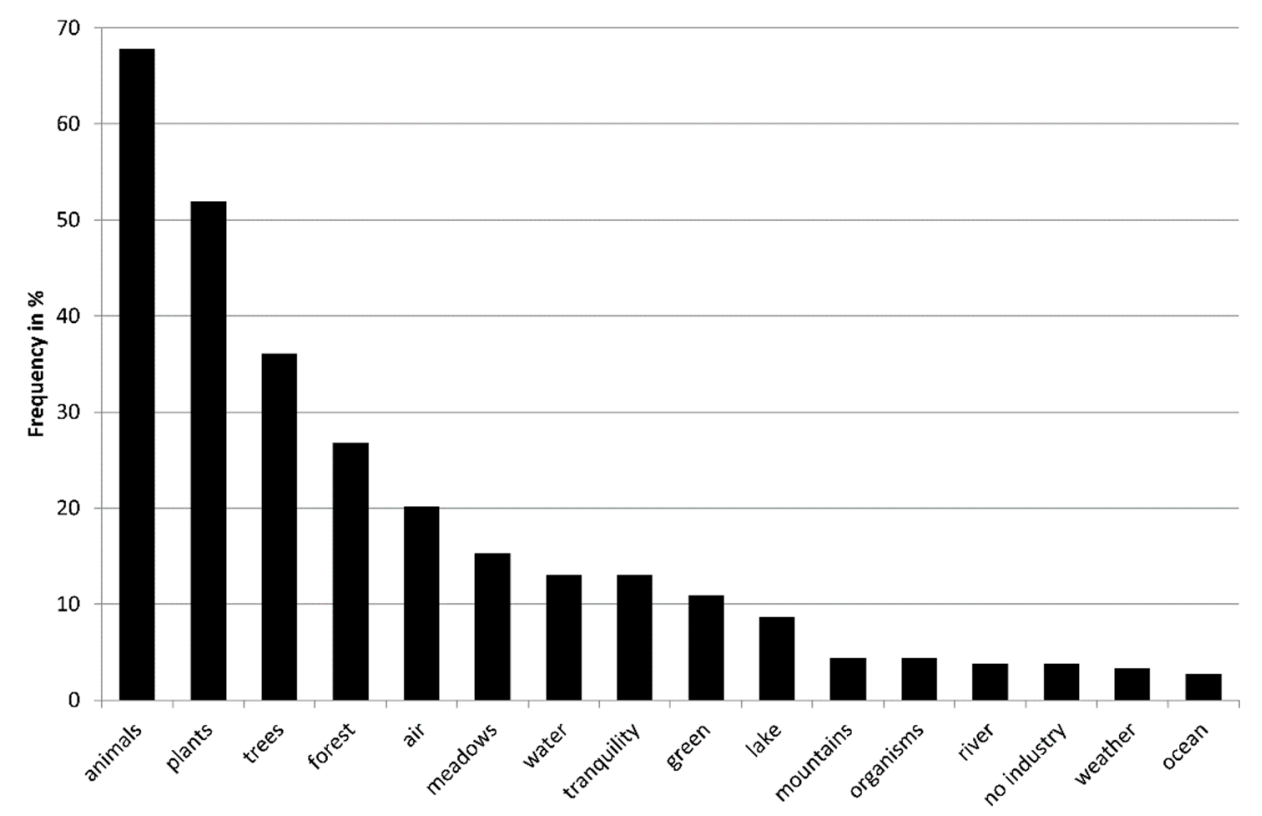

Figure 2. Percentage distribution of the mentioned categories.

\subsection{Discussion}

Especially in environmental psychology, the question of what exactly is understood by the term nature often remains undefined [29]. Additionally, in modern everyday language there is no straightforward way to understand nature. The term is often used to describe green spaces with ecological value [33]. Until now, only a few empirical studies have dealt with the images that humans have of nature. For example 34 [34], examined what people think of when they hear the term nature environment. Abstract terms like "undisturbed by humans", "beautiful" or "peaceful" were often mentioned. It was also found that people's cognitions of what nature is are more ecocentric than anthropocentric [35]. Cultural influences and differences in the perception of nature are also likely. For example, a study in the Netherlands found that native Dutch people tend to have a wilderness image of nature, whereas immigrants tend to have a functional image [36]. There are only very few studies that really deal concretely with what images of nature humans or children have. In another Dutch study, people counted the sea, wind, the sun, but also animals and plants as part of real nature. Particularly important were forests, which $69 \%$ of the participants mentioned [37]. Van den Born et al. [38] discovered that, for example, the rainforest, wind or heathlands were considered 'real' nature.

Our study supports these findings from previous studies and provides a number of new insights into children's perception of nature. The results show that animals and plants in particular are seen as an important part of nature, with the forest and trees being explicitly mentioned by many students. This seems to be conclusive, since about one third of the country where the survey took place (Germany) is covered with forest [39]. Water bodies, meadows and air were also counted as part of nature, as well as abstract terms such as "green" or "silence".

In order to create a survey instrument from the terms mentioned, we tried to graphically represent as many of the terms in Figure 2 as possible. Thus, different animals $(67.8 \%)$, different plants (51.9\%), meadows (15.3\%), and mountains $(4.4 \%)$ were used. The 
three water types (water $13.1 \%$; lake $8.7 \%$; 3.8\% river) were, in order not to overload the illustration, summarized and represented only by a river. The picture works with a lot of green $(10.9 \%)$ and should give an impression of tranquility $(13.1 \%)$. An easy to understand comic style was chosen for the images. The created image was resized to fit into the circle of the INS labeled nature. The circle that represents the person itself was extended by a pictogram of a human. The final illustration is shown in Figure 3 in English and in the Appendix B in German. This extended survey instrument is called Illustrated INS (IINS) or illustrated version of the INS.

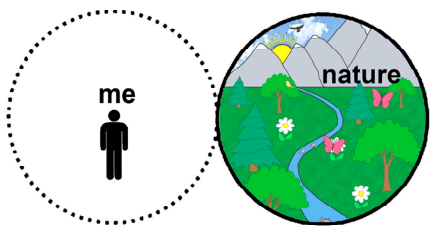

(A)

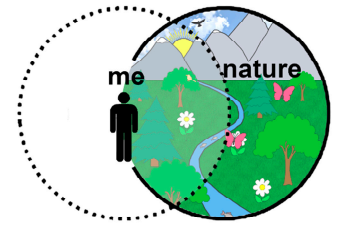

(D)

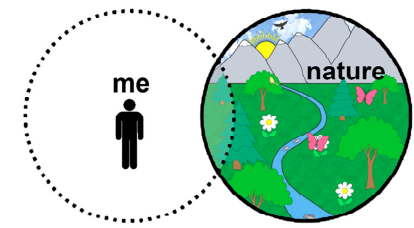

(B)

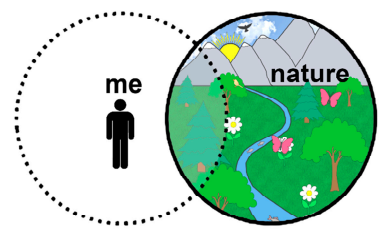

(C)

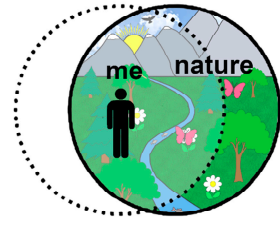

(E)

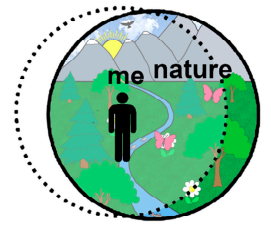

(F)

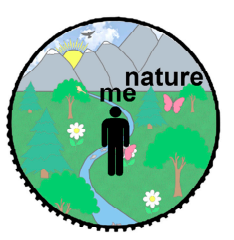

(G)

Figure 3. Finale Version of the Illustrated Inclusion of Nature in Self Scale (IINS).

\section{Study 2}

In study 2, the newly developed IINS and the original INS were tested on students and compared with each other. Additionally, both scales were compared with an established nature connectedness measuring instrument (CNS).

\subsection{Methods}

To test whether the illustrated version of the INS measures the connection to nature as in the original scale by Schultz [12], two homogeneous groups were selected. One group was surveyed with the IINS, the other with the original INS. In addition, the CNS of Mayer and Frantz [5] was also applied in both groups to determine a potential difference in connection to nature. The gender and age distribution in the groups has a potential influence on the connection to nature (e.g., $[40,41])$, so that both factors must be taken into account.

\subsubsection{Participants}

A total of 588 students were surveyed in two consecutive years in the course "Structure and Function of Organisms" at Goethe-University Frankfurt. This is an introductory course in biology studies, which both biology bachelor students as well as teacher trainees in biology in the first semester of their studies have to complete. In the first year (winter semester 2018/19), 322 students (64.3\% female, 33.9\% male, $1.8 \%$ no answer; $\left.\mathrm{M}_{\mathrm{age}}=20.44\right)$ were surveyed. In the following year (winter semester 19/20), 266 new students (62.0\% female, 35.3 male, 2.6 no answer; $M_{\text {age }}=20.51$ ) were questioned. The age and gender distribution is shown in Figure 4. 

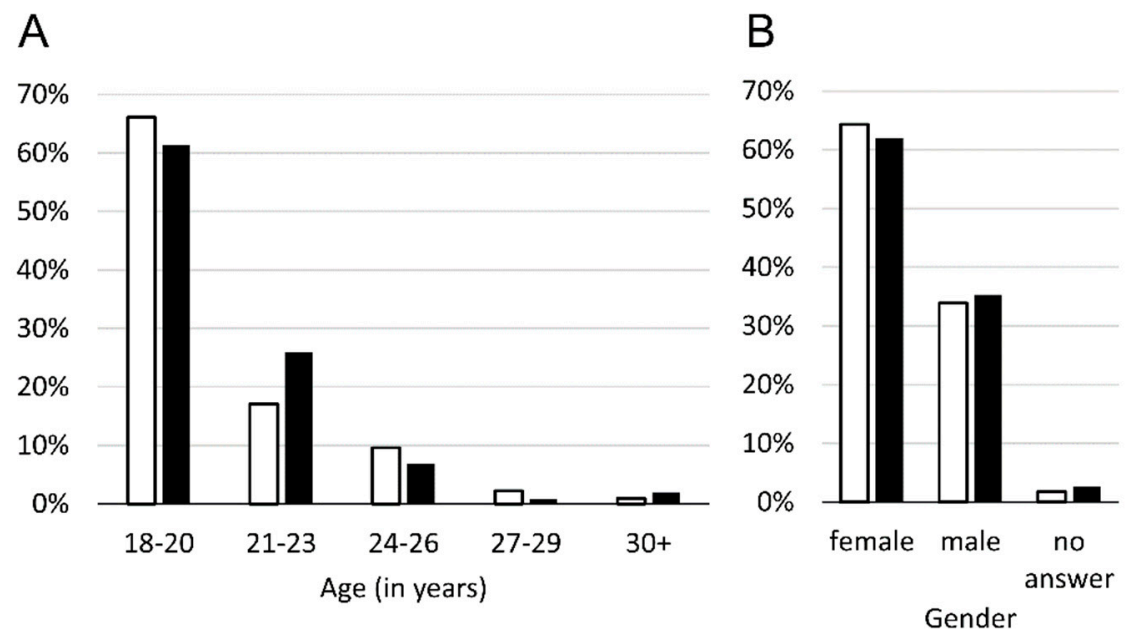

口Group 1 (winter semester 2018/19)

- Group 2 (winter semester 2019/20)

Figure 4. Comparison of the age (A) and gender (B) between the samples. The largest age cohort was the 18 to 20 year-olds in both groups. In terms of gender distribution, the proportion of women was larger in both groups.

The survey was voluntary and all respondents were of legal age at the time of the study. The students were asked to fill in the questionnaire at the beginning of the practical work phase of the course and leave it on the table at the end of the day.

\subsubsection{Instruments}

CNS. Die Connectedness to Nature Scale is a question instrument consisting of 14 items from Mayer and Frantz [5] which aims to measure the affective connection to nature. It has been used in numerous studies $[16,17,40,42]$ and its reliability confirmed repeatedly, also for different languages [43-46]. Even though the instrument has been criticized by some authors for not measuring the emotional connection to nature as it is supposed to [47], its correlation and therefore convergent validity to other measuring instruments of the concept of connection to nature could be proven [48-50]. It can therefore be assumed that the CNS is a suitable instrument for investigating the connection to nature. Since the study was conducted during class time, a shortened version of the CNS was used in order to keep the questionnaire as short and compact as possible. For this purpose, five items with high factor loading from the original study of Mayer and Frantz [5] were selected. The applicability of a shortened CNS was confirmed several times in previous research $[45,46,51]$.

INS. The Inclusion of Nature in Self Scale is a one-dimensional, graphical questioning tool by Schultz [12] following the example of the "Inclusion of Other in the Self Scale" by Aron et al. [52]. It was designed to measure the cognitive component of being connected to nature. It consists of seven pairs of circles, which differ in the degree of overlap. One circle is labeled with "me", the other with "nature" (Appendix A). The participants had to choose the pair of circles that best describes their relationship to nature. The scale ranges from two separate circles (separate from nature) to two completely overlapping circles (one with nature). Despite its simplicity, the instrument shows a strong positive correlation with other instruments for connecting with nature $[44,48,50]$ and was tested and applied in many studies [21-23,53,54].

IINS. The Illustrated Inclusion of Nature in Self Scale that was developed in study 1 (see Appendix B) was also applied. 


\subsubsection{Analysis}

The statistical analysis was performed using IBM SPSS 27. In a first step, a principal component analysis (PCA) of the five CNS items was conducted to verify the single factor structure of the instrument. To determine whether the five CNS items used were suitable for factor analysis, the Bartlett test and the Kaiser-Meyer-Olkin (KMO) test were previously performed. The Kolmogorov-Smirnov was used to test for normal distribution. To check whether the age and gender distribution in the two test groups differed significantly, the Mann-Whitney-U-Test was applied. The same test was performed to compare the INS and CNS values of the two test groups. The Pearson correlation between CNS and INS was calculated for both groups.

\subsection{Results}

For the five $\mathrm{CNS}$ items, the $\mathrm{KMO}$ test approved the sampling adequacy $(\mathrm{KMO}=0.802)$ and the Bartlett test was highly significant $(p<0.001)$, thus meeting the requirements for factor analysis. All items showed a high factor loading $(\mathrm{M}=0.764)$ on a single factor, which explained $58.84 \%$ of the variance. The Cronbach alpha was $\alpha=0.816$ (Table 1 ).

Table 1. Result of the principal component analysis (PCA) with the items of the reduced Connectedness to Nature Scale (CNS).

\begin{tabular}{llc}
\hline & & Factor 1 \\
\hline CNS_1 & I often feel part of the web of life. & 0.855 \\
CNS_2 & I often feel a sense of oneness with natural world around me. & 0.807 \\
CNS_3 & I think of the natural world as a community to which I belong. & 0.783 \\
CNS_4 & I feel as though I belong to the Earth as equally as it belongs to me. & 0.692 \\
CNS_5 & When I think of my life, I imagine myself to be part of a larger cyclical process of living. & 0.685 \\
\hline
\end{tabular}
$\alpha=0.816$.

The comparison of the age and gender distribution between the two student groups showed no significant difference ( $p_{a g e}=0.400$; $p_{\text {gender }}=0.829$ ). Furthermore, the comparison of the CNS and INS scores between the two groups showed no significant differences $\left(p_{C N S}=0.276 ; p_{I N S}=0.247\right)$. The Pearson correlation between the CNS and INS score for the first group (winter semester 2018/19) was $r=0.595(p<0.001)$, for the second group (winter semester 2019/20) $\mathrm{r}=0.618(p<0.001)$.

\subsection{Discussion}

The KMO score $(\mathrm{KMO}=0.802)$ and the significance of the Bartlett test $(p<0.001)$ confirm that the data are appropriate for performing a factor analysis $[55,56]$. The factor analysis of the five CNS items used underlines the single factor structure of the CNS scale. All items show high factor loadings $(>0.685$; average factor loading $=0.766)$ and an acceptable Cronbach alpha of $\alpha=0.816$ [57]. The average factor loading for the shortened scale is significantly higher than for the full scale (Mayer and Frantz [5]; average values between 0.54 and 0.61; see also Olivos et al. [49]). On the other hand, studies with a shortened version of the CNS show similarly high factor loading [42,46] and alpha values [45], as in this study. This confirms that the CNS items used reflect the one-dimensional construct well and that internal consistency is given. Therefore, it is suitable for further analysis.

The comparison of the gender distribution between the two groups tested shows no significant difference $(p=0.829)$. Gender is a much discussed factor in the literature, as it potentially influences various personal variables related to nature (e.g., [58-60]). However, the results are mixed and sometimes contradictory. While some studies have not found a difference between men and women $[5,61,62]$, there is also evidence of a higher level of connection to nature among women [40]. Despite the contradictory results, a different gender distribution between the groups of the study could have led to a distortion of the results. Due to the equal gender distribution between the groups, this can be excluded. The age effect in terms of connection to nature is, however, more explicit. Various studies 
have shown that younger students have higher values of connection to nature than older ones [22,23]. Hughes et al. [41] examined the relationship between connection to nature and age in a large cross-sectional study. It was found that the connection to nature is relatively high for younger children, but declines strongly during puberty. After puberty, there is an increase again, but this does not reach the high starting level. Due to the equal distribution of age and gender in both groups and the same orientation of interests (biology students in their freshman year), it can be assumed that these are homogeneous groups. Thus, a comparison of the instruments across the groups is valid.

The comparison of CNS scores for the two groups shows no significant difference $(p=0.276)$. It can therefore be concluded that there is an equal level of connection to nature in both groups. If the IINS does not distort the result and works as intended, the comparison of the illustrated and original INS values between the two student's groups should not show a significant difference. The Mann-Whitney-U-test confirms that there is no significant difference between the two groups with different INS instruments $(p=0.247)$. It can therefore be assumed that the newly developed IINS measures the connection to nature as effectively as the original scale and that the results even remain comparable. This result is also supported by the correlations of (I)INS and CNS in both groups. For both groups, the correlations between the instruments are in a similar range size $\left(\mathrm{r}_{\text {Group }} 1=0.595\right.$; $\mathrm{r}_{\text {Group } 2}=0.618$ ). The high correlation indicates a high convergence of the two instruments. This result for the original INS and CNS has already been confirmed in various previous studies. For example, 50 [50] found similar correlation values $(r=0.64$ and $r=0.53)$ between INS and CNS in his two studies. Brügger et al. [48] and Olivos et al. [49] also found similar correlations scores $(r=0.66 ; r=0.561$ and $r=0.472)$. The comparison with the literature values suggests that the illustrated version of the INS quantifies the connection to nature like the original version of the INS.

\section{Study 3}

In study 3, the IINS was tested on the actual target group, people with a lower ability to abstract. In addition, it was compared to established nature connection instruments (CNS and NR-6).

\subsection{Methods}

\subsubsection{Participants}

A total of 106 participants were questioned for this sub-study. All participants were students of a German special needs school with a focus on learning support ("Förderschule mit dem Schwerpunkt Lernen"). This type of school is attended by students with special needs or various limitations (e.g., cognitive) for which the attendance of a regular school is often limited. Before the study was conducted, it was registered and approved by the Ministry of Education and Cultural Affairs ("Hessisches Kultusministerium"), which is responsible for the supervision of schools. Part of this procedure was also the approval of the school administration and the school conference of the school consulted. Prior to the survey, the parents were informed in writing about the purpose of the study, the voluntariness of the survey and data protection and were asked for their written consent. The study participants were also informed about the voluntariness of participation. All data were collected anonymously and used for research purposes only. Questionnaires with patterns (e.g., the same field ticked for all questions) were excluded from the analysis. Overall, $45 \%$ of the participants were female, $54 \%$ male and $1 \%$ did not want to give any information about their gender. The age distribution ranged from 9 to 14 and all students were diagnosed with special educational needs in the area of learning. special learning support.

The individual questions of the questionnaire were read out to the class by a member of the university staff and after each question the students were given some time to check the boxes. Before, the functionality of the Likert-Scale was explained to the students using everyday examples. If there was any uncertainty about the meaning of individual words, 
help was given. This supporting action was necessary because without this help (e.g., due to reading and comprehension difficulties), the completion of the questionnaire would not have been possible. It was made sure that the individual questions were read out as neutrally as possible so that those being tested were not influenced by the way of speaking.

\subsubsection{Instruments}

As in study 2, the IINS and the shortened version of the CNS were used for this study. In addition, the nature relatedness scale (NR) of Nisbet et al. [6] was used to measure the connection to nature. This is a construct of nature connection, which describes the individual relationship to the natural world. Thus, the concept includes the appreciation and understanding of connectedness to other living beings [6]. The scale has received much attention in environmental research and has been used in numerous studies (e.g., $[6,15,63,64]$ ). To keep the questionnaire as compact as possible for the students, a shortened version of the NR, the NR-6, was used. This version was developed by Nisbet and Zelenski [65] and shows high internal consistency, validity and reliability, similar to the original scale. Therefore, the instrument is particularly suitable for questionnaires where time and space are limited [65]. This instrument has also been used in numerous studies (e.g., [19,65,66]). Since it could be assumed that at least some of the students in our survey group have no idea what the term spirituality means, item three of NR-6 was not included in the survey, which reduced the number of items to five.

\subsubsection{Analysis}

A PCA was conducted with the five NR items to verify the factor structure of the construct for our target group. Prior to this, the Bartlett test and the KMO test was used to examine whether the data were suitable for factor analysis. To determine the correlation between the three test instruments, the Pearson correlation was calculated.

\subsection{Results}

The Bartlett test was highly significant $(p<0.001)$ and the KMO test approved the sampling adequacy $(\mathrm{KMO}=0.769)$, so the requirements for a factor analysis were fulfilled. All items showed a high factor loading on a single factor, which explained $50.47 \%$ of the variance. The Cronbach alpha was $\alpha=0.758$ (Table 2).

Table 2. Result of the principal component analysis with the five items of the nature relatedness scale (NR-6).

\begin{tabular}{llc}
\hline & & Factor 1 \\
\hline NR_1 & I feel very connected to all living things and the earth. & 0.806 \\
NR_2 & My relationship to nature is an important part of who I am. & 0.803 \\
NR_3 & I take notice of wildlife wherever I am. & 0.694 \\
NR_4 & My ideal vacation spot would be a remote, wilderness area. & 0.688 \\
NR_5 & I always think about how my actions affect the environment. & 0.523 \\
\hline
\end{tabular}

$$
\alpha=0.758 \text {. }
$$

The Pearson correlation between the IINS and the CNS was $r=0.570$, between the IINS and NR-6 $r=0.605$ and between CNS and NR-6 $r=0.844$ (Figure 5). 


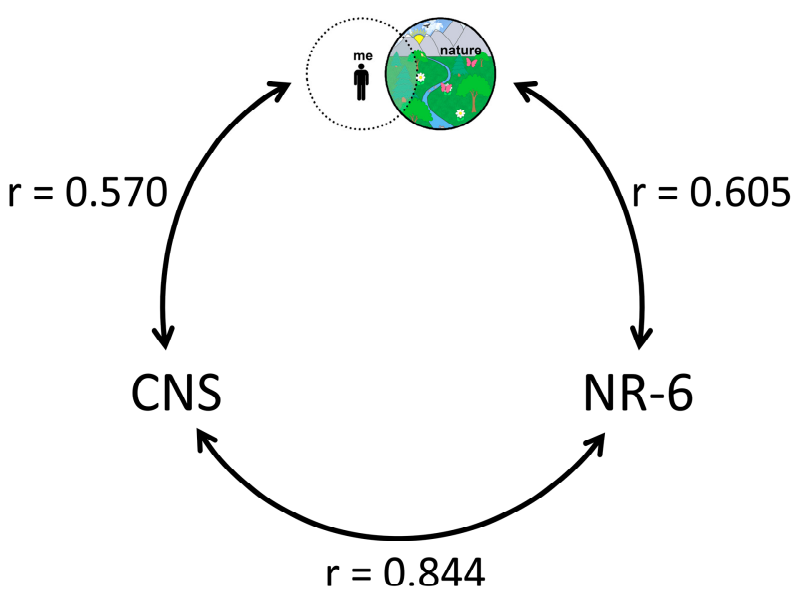

Figure 5. Correlations between the nature connection scales used in study 3.

\subsection{Discussion}

The results of the factor analysis confirm the single factor solution of the NR scale used [65] and the factor loadings are comparable with previous studies [66]. The Cronbach alpha score also confirms the reliability and internal consistency of the shortened and translated scale. To check whether the newly developed graphical version of the INS measures the connection to nature in the same way as established instruments, the convergent validity of the scale must be confirmed. To determine the convergent validity, the Pearson correlation is often used [67] and should in this context not be less than a value of $r=0.5$ [68]. Our results thus, confirm the convergent validity of the IINS compared to the established instruments. The correlations we measured are not only above the cut off value of $r=0.5$, but also come very close to the literature values $[5,48-50,62,63,69]$. Previous studies have already shown that the correlation between the CNS and NR is relatively high. In two studies, Tam [50] found correlation values of $r=0.83$ and $r=0.76$. Howell et al. [63] found a slightly lower but still strong correlation of $r=0.61$. Furthermore, Nisbet et al. [6] confirmed that there might be overlaps between the CNS and the NR. Our result is also in this size range $(\mathrm{r}=0.844)$ and confirms this conclusion.

The correlations between CNS and INS are described as less strong in the literature. They are in the range between $r=0.472$ and $r=0.66[5,48-50,62,69]$. However, most of the values are around $r=0.55$ and are therefore similar to our results $(r=0.570)$. This leads to the conclusion that the illustrated version of the INS has a similar convergent validity to the CNS as the original INS.

For the INS and the NR the literature has found strong correlations between the scales $[50,65]$. Such a strong correlation could also be measured in our study $(r=0.605)$. In conclusion, our results of the correlation analysis indicate that there is a similarly good convergent validity between CNS, NR and the IINS as between CNS, NR and the original INS. This confirms that the IINS measures the connection to nature for our target group as precisely as the original INS. Therefore, the illustrated version of the INS can be used as a useful alternative for measuring the connection to nature, especially for groups, as in our case, where other instruments are not suitable.

\section{Limitations}

Although the study was conducted with great care, some limitations need to be addressed. The developed illustrated scale reflects the idea of nature from a Western cultural area. It can be assumed people in another cultural areas, for example in the Arab world, have a different idea of nature [36]. Therefore, it has yet to be tested whether it provides precise results outside of the Western cultural area. For the comparison of the different instruments with the IINS, shortened measuring instruments of the CNS and the NR-21 scale were used. Although previous studies have shown that reduced versions of the scales meet the evaluation criteria, have sufficient psychometric properties, and 
measure the construct well $[45,46,51,65]$, it is possible that information was lost and the result influenced by the use of reduced scales.

\section{Conclusions}

The three studies carried out provide an important research contribution to environmental education research. Until now, there have been only a limited number of studies that investigate what people exactly understand by the term nature (e.g., [37]). The results of study 1 thus provide important information about what children consider to be nature and what they associate with this term. From this, an illustrated measuring instrument could be developed, which was tested in study 2 on a large number of students. Since no significant difference between the new IINS and the original INS could be found, first indications were given that both instruments are similar enough to capture the same construct of connection to nature. Afterwards, the IINS was tested on the actual target group in study 3 . The results confirm the high convergent validity of the new instrument. Thus, this study provides environmental education research and environmental psychology with a measuring instrument that is appropriate for measuring the connection to nature of people with a lower ability of abstraction (such as young children or people with mental impairments). In future studies, the new instrument can be used to assess teaching approaches in terms of their ability to foster a connection to nature for younger students or students with learning disabilities. This will help to identify potential factors that can improve nature connectedness among this group in particular. With this knowledge, biology and conservation lessons can be planned, evaluated and improved to further connect their students with nature. Especially for environmental education institutions in the primary or special education sector, the instrument is very interesting, because it was designed to fit the needs of the target group and offers a valid way to measure the connection to nature of their participants.

Because the IINS also provides accurate results for adult students, future longitudinal studies can be used to examine the development of nature connectedness from early childhood through adulthood. The results remain comparable to other studies that used the original INS, as the IINS does not affect the results.

Author Contributions: Conceptualization, M.W.K., T.B., P.W.D. and V.W.; data curation, M.W.K.; funding acquisition, P.W.D. and V.W.; investigation, M.W.K.; methodology, M.W.K., T.B., P.W.D. and V.W.; project administration, V.W.; supervision, P.W.D. and V.W.; validation, M.W.K. and V.W.; visualization, M.W.K. and P.W.D.; writing-original draft, M.W.K. and T.B.; writing-review and editing, M.W.K., P.W.D. and V.W. All authors have read and agreed to the published version of the manuscript.

Funding: This research received no external funding.

Data Availability Statement: The raw data supporting the conclusions of this article will be made available by the authors, without undue reservation, to any qualified researcher.

Acknowledgments: This study was partly supported by the Opel-Zoo Foundation Professorship in Zoo Biology from the "von Opel Hessische Zoostiftung".

Conflicts of Interest: The authors declare no conflict of interest. 


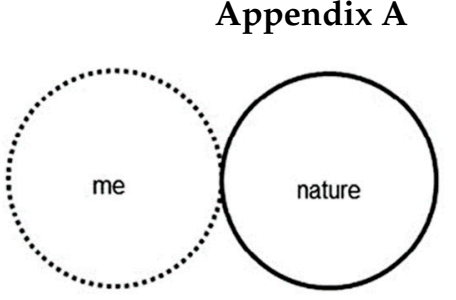

(A)

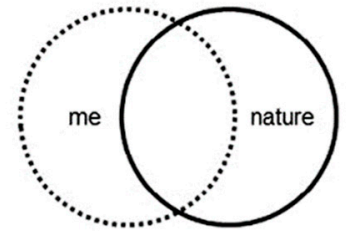

(D)

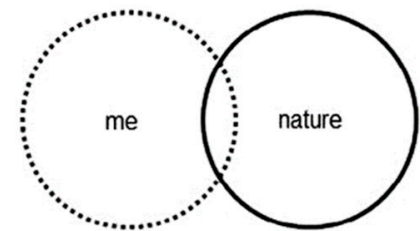

(B)

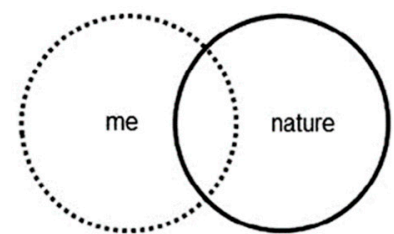

(C)

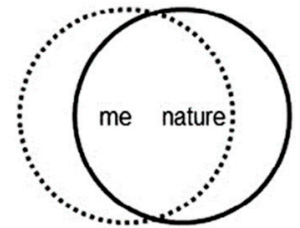

(E)

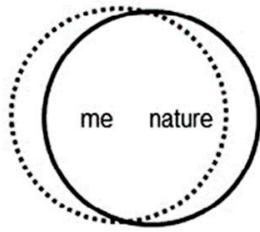

(F)

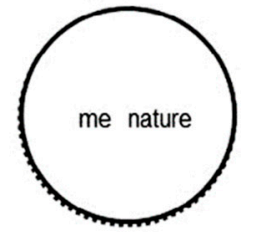

(G)

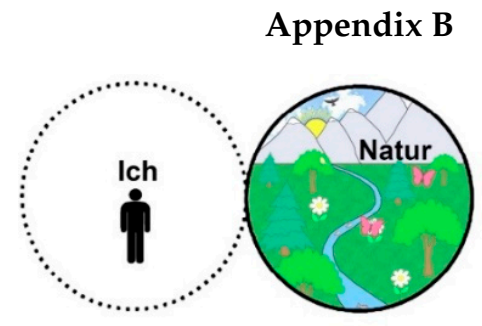

(A)

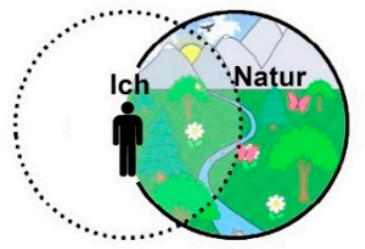

(D)

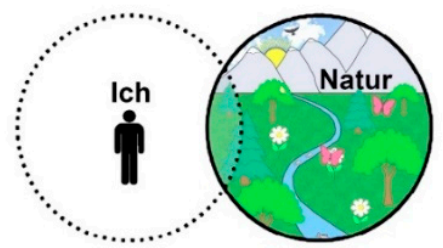

(B)

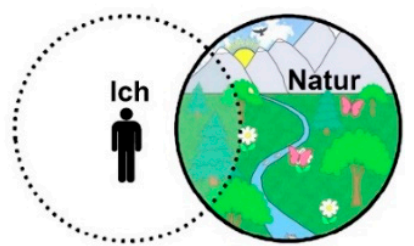

(C)

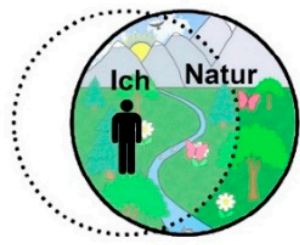

(E)

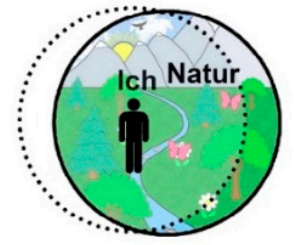

(F)

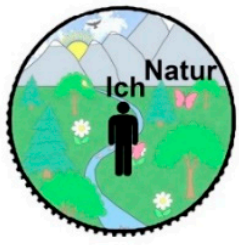

(G)

\section{References}

1. Leopold, A. A Sand County Almanac: With Other Essays on Conservation from Round River; Ballantine Books: New York, NY, USA, 1949.

2. Clayton, S. Environmental identity: A conceptual and an operational definition. In Identity and the Natural Environment: The Psychological Significance of Nature; Clayton, S., Opotow, S., Eds.; MIT Press: Cambridge, UK, 2003; pp. 45-65.

3. Walton, T.N.; Jones, R.E. Ecological identity: The development and assessment of a measurement scale. Environ. Behav. 2018, 50, 657-689. [CrossRef]

4. Kals, E.; Schumacher, D.; Montada, L. Emotional affinity toward nature as a motivational basis to protect nature. Environ. Behav. 1999, 31, 178-202. [CrossRef]

5. Mayer, F.S.; Frantz, C.M. The connectedness to nature scale: A measure of individuals' feeling in community with nature. J. Environ. Psychol. 2004, 24, 503-515. [CrossRef]

6. Nisbet, E.K.; Zelenski, J.M.; Murphy, S.A. The Nature Relatedness scale: Linking individuals' connection with nature to environmental concern and behavior. Environ. Behav. 2009, 41, 715-740. [CrossRef]

7. Jordan, M. Nature and Self-An Ambivalent Attachment? Ecopsychology 2009, 1, 26-31. [CrossRef]

8. Kaiser, F.G.; Roczen, N.; Bogner, F.X. Competence formation in environmental education: Advancing ecology-specific rather than general abilities. Umweltpsychologie 2008, 12, 56-70.

9. Geng, L.; Xu, J.; Ye, L.; Zhou, W.; Zhou, K. Connections with nature and environmental behaviors. PLoS ONE 2015, 10, e0127247. [CrossRef] [PubMed] 
10. Dunlap, R.E.; van Liere, K.D.; Mertig, A.G.; Jones, R.E. New trends in measuring environmental attitudes: Measuring endorsement of the New Ecological Paradigm: A revised NEP scale. J Soc. Isssues 2000, 56, 425-442. [CrossRef]

11. Cheng, J.C.-H.; Monroe, M.C. Connection to nature. Environ. Behav. 2012, 44, 31-49. [CrossRef]

12. Schultz, P.W. Inclusion with nature: The psychology of human-nature relations. In Psychology of Sustainable Development; Schmuck, P., Schultz, P.W., Eds.; Springer: Boston, MA, USA, 2002; pp. 61-78. [CrossRef]

13. Dutcher, D.D.; Finley, J.C.; Luloff, A.E.; Johnson, J.B. Connectivity with nature as a measure of environmental values. Environ. Behav. 2007, 39, 474-493. [CrossRef]

14. Schultz, P.W.; Tabanico, J. Self, identity, and the natural environment: Exploring implicit connections with nature. J. Appl. Soc. Pyschol. 2007, 37, 1219-1247. [CrossRef]

15. Nisbet, E.K.; Zelenski, J.M.; Murphy, S.A. Happiness is in our nature: Exploring nature relatedness as a contributor to subjective well-being. J. Happiness Stud. 2011, 12, 303-322. [CrossRef]

16. Cervinka, R.; Röderer, K.; Hefler, E. Are nature lovers happy? On various indicators of well-being and connectedness with nature. J. Health Psychol. 2012, 17, 379-388. [CrossRef]

17. Mayer, F.S.; Frantz, C.M.; Bruehlman-Senecal, E.; Dolliver, K. Why is nature beneficial? Environ. Behav. 2009, 41, 607-643. [CrossRef]

18. Capaldi, C.A.; Dopko, R.L.; Zelenski, J.M. The relationship between nature connectedness and happiness: A meta-analysis. Front. Psychol. 2014, 5, 976. [CrossRef]

19. Zelenski, J.M.; Nisbet, E.K. Happiness and feeling connected: The distinct role of nature relatedness. Environ. Behav. 2014, 46, 3-23. [CrossRef]

20. Ryan, R.M.; Weinstein, N.; Bernstein, J.; Brown, K.W.; Mistretta, L.; Gagné, M. Vitalizing effects of being outdoors and in nature. J. Environ. Psychol. 2010, 30, 159-168. [CrossRef]

21. Kossack, A.; Bogner, F.X. How does a one-day environmental education programme support individual connectedness with nature? J. Biol. Educ. 2012, 46, 180-187. [CrossRef]

22. Liefländer, A.K.; Fröhlich, G.; Bogner, F.X.; Schultz, P.W. Promoting connectedness with nature through environmental education. Environ. Educ. Res. 2013, 19, 370-384. [CrossRef]

23. Braun, T.; Dierkes, P. Connecting students to nature-How intensity of nature experience and student age influence the success of outdoor education programs. Environ. Educ. Res. 2017, 23, 937-949. [CrossRef]

24. Mullenbach, L.E.; Andrejewski, R.G.; Mowen, A.J. Connecting children to nature through residential outdoor environmental education. Environ. Educ. Res. 2019, 25, 365-374. [CrossRef]

25. Schultz, P.W.; Shriver, C.; Tabanico, J.J.; Khazian, A.M. Implicit connections with nature. J. Environ. Psychol. 2004, 24, 31-42. [CrossRef]

26. Martin, C.; Czellar, S. The extended Inclusion of Nature in Self scale. J. Environ. Psychol. 2016, 47, 181-194. [CrossRef]

27. Hellbrück, M.; Fischer, J. Umweltpsychologie. ein Lehrbuch; Hogrefe: Göttingen, Germany, 1999.

28. Clayton, S.; Opotow, S. Identity and the Natural Environment: The Psychological Significance of Nature; MIT Press: Cambridge, UK, 2003.

29. Ives, C.D.; Giusti, M.; Fischer, J.; Abson, D.J.; Klaniecki, K.; Dorninger, C.; Laudan, J.; Barthel, S.; Abernethy, P.; Martín-López, B.; et al. Human-nature connection: A multidisciplinary review. Curr. Opin. Environ. Sustain. 2017, 26-27, 106-113. [CrossRef]

30. Ducarme, F.; Couvet, D. What does 'nature' mean? Palgrave Commun. 2020, 6, 194. [CrossRef]

31. Oxford Advanced Learner's Dictionary. Definition of Nature Noun from the Oxford Advanced Learner's Dictionary. Available online: https:/ / www.oxfordlearnersdictionaries.com/definition/english/nature_1?q=nature (accessed on 19 August 2020).

32. Cambridge Dictionary. Meaning of Nature in English. Available online: https://dictionary.cambridge.org/us/dictionary/engli sh/nature?q=nature (accessed on 19 August 2020).

33. Corner, A.; Parkhill, K.; Pidgeon, N.; Vaughan, N.E. Messing with nature? Exploring public perceptions of geoengineering in the UK. Global Environ. Chang. 2013, 23, 938-947. [CrossRef]

34. Vining, J.; Merrick, M.S.; Price, E.A. The distinction between humans and nature: Human perceptions of connectedness to nature and rlements of the natural and unnatural. Hum. Ecol. Rev. 2008, 15, 1-11.

35. van den Berg, A.E.; Vries, D.H.; Vlek, C.A.J. Images of nature, environmental values, and landscape preference: Exploring their interrelationships. In Visions of Nature: A Scientific Exploration of People's Implicit Philosophies Regarding Nature in Germany, The Netherlands and The United Kingdom; van den Born, R.J.G., Lenders, R.H.J., deGroot, W.T., Eds.; LIT: Münster, Germany, 2006.

36. Buijs, A.E.; Elands, B.H.M.; Langers, F. No wilderness for immigrants: Cultural differences in images of nature and landscape preferences. Landsc. Urban Plan. 2009, 91, 113-123. [CrossRef]

37. Buijs, A.E.; Volker, C.M. Publiek Draagvlak voor Natuur en Natuurbeleid (The Public Basis of Nature and Nature Policy); Research Report; DLO-Staring Centrum: Wageningen, The Netherlands, 1997.

38. Van den Born, R.J.G.; Lenders, R.H.J.; de Groot, W.T.; Huijsman, E. The new biophilia: An exploration of visions of nature in Western countries. Environ. Conserv. 2001, 28, 65-75. [CrossRef]

39. Statistisches Bundesamt. Land- und Forstwirtschaft, Fischerei: Bodenfläche nach Art der tatsächlichen Nutzung. Available online: https:/ / www.destatis.de/DE/Themen/Branchen-Unternehmen/Landwirtschaft-Forstwirtschaft-Fischerei/Flaechen nutzung/Publikationen/Downloads-Flaechennutzung/bodenflaechennutzung-2030510177004.pdf?_blob=publicationFile (accessed on 19 August 2020). 
40. Zhang, J.W.; Howell, R.T.; Iyer, R. Engagement with natural beauty moderates the positive relation between connectedness with nature and psychological well-being. J. Environ. Psychol. 2014, 38, 55-63. [CrossRef]

41. Hughes, J.; Rogerson, M.; Barton, J.; Bragg, R. Age and connection to nature: When is engagement critical? Front. Ecol. Environ. 2019, 17, 265-269. [CrossRef]

42. Gosling, E.; Williams, K.J.H. Connectedness to nature, place attachment and conservation behaviour: Testing connectedness theory among farmers. J. Environ. Psychol. 2010, 30, 298-304. [CrossRef]

43. Matas-Terrón, A.; Elósegui-Bandera, E. Psychometric properties of the Connectedness to Nature Scale tested on a sample of university students. Psyecology 2012, 3, 101-111. [CrossRef]

44. Navarro, O.; Olivos, P.; Fleury-Bahi, G. "Connectedness to Nature Scale": Validity and reliability in the French context. Front. Psychol. 2017, 8, 2180. [CrossRef] [PubMed]

45. Pasca, L.; Aragonés, J.I.; Coello, M.T. An analysis of the connectedness to nature scale based on item response theory. Front. Psychol. 2017, 8, 1330. [CrossRef] [PubMed]

46. Kleespies, M.W.; Dierkes, P.W. Exploring the construct of relational values: An empirical approach. Front. Psychol. 2020, 11, 209. [CrossRef]

47. Perrin, J.L.; Benassi, V.A. The connectedness to nature scale: A measure of emotional connection to nature? J. Environ. Psychol. 2009, 29, 434-440. [CrossRef]

48. Brügger, A.; Kaiser, F.G.; Roczen, N. One for All? Eur. Psychol. 2011, 16, 324-333. [CrossRef]

49. Olivos, P.; Aragonés, J.I.; Amérigo, M. The connectedness to nature scale and its relationship with environmental beliefs and identity. Int. J. Hisp. Psychol. 2011, 4, 5-19.

50. Tam, K.-P. Concepts and measures related to connection to nature: Similarities and differences. J. Environ. Psychol. 2013, 34, 64-78. [CrossRef]

51. Rosa, C.D.; Collado, S.; Profice, C.C.; Pires, P.P. The 7-items version of the connectedness to nature scale: A study of its validity and reliability with Brazilians. Curr. Psychol. 2020. [CrossRef]

52. Aron, A.; Aron, E.N.; Smollan, D. Inclusion of Other in the Self Scale and the structure of interpersonal closeness. J. Personal. Soc. Psychol. 1992, 63, 596-612. [CrossRef]

53. Sellmann, D.; Bogner, F.X. Effects of a 1-day environmental education intervention on environmental attitudes and connectedness with nature. Eur. J. Psychol. Educ. 2013, 28, 1077-1086. [CrossRef]

54. Kleespies, M.W.; Gübert, J.; Popp, A.; Hartmann, N.; Dietz, C.; Spengler, T.; Becker, M.; Dierkes, P.W. Connecting high school students with nature-How different guided tours in the zoo influence the success of extracurricular educational programs. Front. Psychol. 2020, 11, 1804. [CrossRef]

55. Dziuban, C.D.; Shirkey, E.C. When is a correlation matrix appropriate for factor analysis? Some decision rules. Psychol. Bull. 1974, 81, 358-361. [CrossRef]

56. Kaiser, H.F. An index of factorial simplicity. Psychometrika 1974, 39, 31-36. [CrossRef]

57. Tavakol, M.; Dennick, R. Making sense of Cronbach's alpha. Int. J. Med. Educ. 2011, 2, 53-55. [CrossRef]

58. Alp, E.; Ertepinar, H.; Tekkaya, C.; Yilmaz, A. A tatistical analysis of children's environmental knowledge and attitudes in Turkey. International Res. Geogr. Environ. Educ. 2006, 15, 210-223. [CrossRef]

59. Braun, T.; Cottrell, R.; Dierkes, P. Fostering changes in attitude, knowledge and behavior: Demographic variation in environmental education effects. Environ. Educ. Res. 2018, 24, 899-920. [CrossRef]

60. Zelezny, L.C.; Chua, P.-P.; Aldrich, C. New ways of thinking about environmentalism: Elaborating on gender differences in environmentalism. J. Soc. Isssues 2000, 56, 443-457. [CrossRef]

61. Di Fabio, A.; Rosen, M. Accounting for individual differences in connectedness to nature: Personality and gender differences. Sustainability 2019, 11, 1693. [CrossRef]

62. Kleespies, M.W.; Dierkes, P.W. Impact of biological education and gender on students' connection to nature and relational values. PLoS ONE 2020, 15, e0242004. [CrossRef]

63. Howell, A.J.; Dopko, R.L.; Passmore, H.-A.; Buro, K. Nature connectedness: Associations with well-being and mindfulness Personal. Individ. Differ. 2011, 51, 166-171. [CrossRef]

64. Dean, J.H.; Shanahan, D.F.; Bush, R.; Gaston, K.J.; Lin, B.B.; Barber, E.; Franco, L.; Fuller, R.A. Is nature relatedness associated with better mental and physical health? Int. J. Environ. Res. Public Health 2018, 15, 1371. [CrossRef] [PubMed]

65. Nisbet, E.K.; Zelenski, J.M. The NR-6: A new brief measure of nature relatedness. Front. Psychol. 2013, 4, 813. [CrossRef]

66. Obery, A.; Bangert, A. Exploring the influence of nature relatedness and perceived science knowledge on proenvironmental behavior. Educ. Sci. 2017, 7, 17. [CrossRef]

67. Lehmann, D.R. An alternative procedure for assessing convergent and discriminant validity. Appl. Psychol. Meas. 1988, 12, 411-423. [CrossRef]

68. Carlson, K.D.; Herdman, A.O. Understanding the Impact of convergent validity on research results. Organ. Res. Methods 2012, 15, 17-32. [CrossRef]

69. Davis, J.L.; Le, B.; Coy, A.E. Building a model of commitment to the natural environment to predict ecological behavior and willingness to sacrifice. J. Environ. Psychol. 2011, 31, 257-265. [CrossRef] 